\title{
A Practical Research on Improving Reader's Reading Literacy by Using WeChat Service under the Perspective of PIRLS and PISA2018
}

\author{
Lina Li \\ University Library and Information Center, Heilongjiang Bayi Agricultural University, Daqing, China \\ Email: byndcscy@126.com
}

How to cite this paper: Li, L. N. (2018). A Practical Research on Improving Reader's Reading Literacy by Using WeChat Service under the Perspective of PIRLS and PISA2018. Creative Education, 9, 1706-1712. https://doi.org/10.4236/ce.2018.911124

Received: June 20, 2018

Accepted: August 28, 2018

Published: August 31, 2018

Copyright $\odot 2018$ by author and Scientific Research Publishing Inc. This work is licensed under the Creative Commons Attribution International License (CC BY 4.0).

http://creativecommons.org/licenses/by/4.0/

\section{cc) (i) Open Access}

\begin{abstract}
With the effective development of PIRLS and PISA2018 in China, research on reading literacy has developed more and more, while reading literacy has become a key indicator of a country's soft power. The university library is an important place to cultivate college students' reading literacy and has the responsibility of reading education. The development of WeChat services in colleges and universities provides a new way for their reading literacy training. Taking the library of Heilongjiang Bayi Agricultural University as an example, this paper expounds the construction of WeChat platform and the situation of WeChat service, and puts forward the main ways of improving the reading literacy of college students according to the actual work, aiming at giving full play for the university library to play their important role in the terms of cultivating the reading literacy of college students.
\end{abstract}

\section{Keywords}

WeChat Public Platform, WeChat Service, Reading Literacy, Reading Promotion

\section{Introduction}

PIRLS (International Reading Literacy Progress Study) is a global student reading literacy transnational (regional) and diachronic comparative evaluation study initiated and organized by the International Association for Educational Achievement Evaluation (IEA). The evaluation target is 9 - 10 years old students, in order to monitor the progress of reading literacy of students in various countries (regions) (Zhang, 2017).

PISA (International Student Assessment Program) is an international student 
evaluation program planned by the Organisation for Economic Co-Operation and Development (OECD) for reading, mathematics, and scientific literacy near the end of compulsory education ( 15 years old). The main target is to evaluate whether the knowledge and skills of students are needed for future life, and the ability to apply their knowledge and skills to solve problems in real life ( $\mathrm{Yu}$, Song, \& Wang, 2017).

Reading literacy refers to the ability of individuals to effectively seek information, understand usage, and reflect on written texts in order to achieve personal development goals, increase knowledge, develop potential, and participate in social life (He \& Wang, 2017). PISA2018 regards reading literacy as the main test area. The OECD regards the proportion of students who have reached the highest reading level in each country as the basis for the future competitiveness of these countries. Reading literacy has become a key indicator of a country's soft power, involving the competitiveness of countries and individuals. In recent years, the study of reading literacy has been paid more and more attention. The author retrieves 943 articles on CNKI with the keyword "reading literacy" as the key word. But with the search of "college + Reading Literacy" as the key words, only 86 articles are retrieved, which is less than $10 \%$. There are some deficiencies in the study of College Students' reading literacy education. University libraries with rich resources, platforms and talents should be devoted to exploring reading education and promotion services, and improving students' reading literacy (Ji \& Wang, 2014).

Today, with the rapid development of big data and new media, the WeChat platform is quickly used by university libraries in a short period of time. Due to its timely, accurate and flexible features in message push, business processing and interactive communication, it has become a feature. The library is an important starting point for all kinds of joint work. This paper takes the Heilongjiang Bayi Agricultural University Library as an example to introduce the strategy of WeChat service in the field of improving readers' reading literacy, aiming to provide reference for other libraries.

\section{WeChat Platform Construction}

In October 2013, Heilongjiang Bayi Agricultural University Library opened WeChat service and completed the certification work in 2016. The public name is "August Agricultural University Library", the English name is BYNDLIB, the icon is library building, and the service type is subscription number. Because Heilongjiang Bayi Farms and Farms has a long name, it uses the method of "school name abbreviation + library" to name it, which is convenient for readers to search. In combination with the current business, we set up four modules: MicroBook, Cloud Reading, Service and Information Push. The WeChat platform is directly linked to the Huiwen system. The reader can perform bibliographic inquiry, renewal, appointment, report loss, and view the history of borrowing on the platform. Direct links to superstar mobile libraries, blogs, audio, 
blogs, microblogs, open classes, etc., can read more than millions of e-book journals. The service section is equipped with the "Shuxiangnongda" and subject services, including the live-action library, Wang Zhen lecture hall, reading salon, theme activities, etc. Readers can read the specific introduction of each event, the recent event preview, and the past event record. Not only can the reader get the activity information in the first time, but also can continue to publicize the activities carried out in the past. Using the platform's graphic message function can regularly push the latest service information to users.

\section{WeChat Service Situation}

The number of users on WeChat platform is 8606 , accounting for about $50 \%$ of the total students, and pushes up more than 3 times a week. The WeChat platform has three first-level menus which are Micro-School, Cloud Reading, and Service. After the reader pays attention to the public account, they can enter the main page of the platform. When the user first pays attention to the platform, the background will send a text menu to the user, and the user can also achieve the above three main functions by replying to the keyword. Users who have paid attention to the platform can use the platform services in the following two ways: first, use the platform function through the selection of menu items; second, obtain the platform service function by replying to the keywords.

\subsection{Micro Library}

The micro-library menu includes my library, borrowing information, mobile library, client download, binding/unbinding five content. With the continuous expansion of the use of Internet mobile terminals, the dominant position of mobile Internet has been continuously strengthened, and the scale of application of mobile terminal devices has been increasing. As an extension of the library mobile service, the mobile library effectively meets the needs of the readers who cannot go to the library. As a form of mobile library, the WeChat platform micro-library module can not only serve the readers of the school, but also the readers of the foreign school can still use the book search function.

\subsection{Cloud Reading}

The cloud-reading menu includes five things: vocal, open class, blog microblog, imaginative star, and subscription center. With the continuous development of network information technology, e-reading has become the most popular reading method for readers. Readers can use mobile phones to read or download online on the Internet. The cloud-reading module of WeChat platform provides readers with cheap and diversified reading materials to meet the needs of readers for e-reading.

\subsection{Service}

The service menu includes three contents: the book Shannon University, the 
subject service, and the new student column. Among them, "Shuxiangongda" is the entrance to read and promote various activities, which can satisfy the readers' various reading needs, and is also a window to attract readers into the world of reading. Subject services can meet the needs of readers for literature acquisition, research, and investigation. The Freshman column provides guidance and assistance to new readers who have not used the library, helping them to quickly learn about the library's resources and activities, and to master the various skills.

\subsection{Graphic Message}

The WeChat platform pushes the latest information to the user through the group sending graphic message. The user can click to read the full-text content, and can also view the original webpage address through the "read original text" connected by the WeChat terminal. The graphic message is divided into multiple graphic messages and single graphic messages. The combination of graphic messages and custom menus can reduce the difficulty for users to use the platform (Li, 2017).

Multi-text message. Limited by the WeChat service provider, the platform can only send a message to the user every day. In order to increase the capacity of information, the colorful is distributed in the form of multiple graphic messages.

Single graphic message. For the transmission of information for a particular service item, a single graphic message is used. Single-text messages can realize the full functionality of multi-text messages and add a summary function. Users can choose whether to read the full text further by reading the abstract.

\subsection{Auto Reply}

An automatic reply was added. When readers first pay attention to the platform, they still don't understand the functions of the platform. The platform needs to design an easy-to-understand and easy-to-understand automatic reply content, which is convenient for users to understand the functions of the platform for subsequent operations.

The message is automatically replied automatically. When the reader uses the platform and replies to keywords that are not set on the platform, the reader cannot obtain valid information. At this point, the platform will automatically reply with a message, so that users can understand the keyword settings of the platform.

Key words automatic reply. The reader obtains the information corresponding to the keyword by replying to the keywords that are usually edited. The keywords connected to the message can be text, picture, voice, video and graphic message.

\section{The Main Way to Improve Literacy Improvement}

\subsection{Provide Massive Resources}

During March 2017 to April, Haixia Xin, Huiru Wu and others carried out an 
investigation of the current situation of university students' reading in many universities of Guangdong province. The statistics of 755 effective reclaimed rolls have been found that $41.72 \%$ of college students used the most reading method in the past year to read WeChat tweets, and $14.04 \%$ of college students read forums, blogs, and Weibo articles, both of which were based on social networks. It shows that more than half of the most commonly used reading methods for college students are social network reading. $25.96 \%$ of college students spend the most reading time on e-books, and only $18.28 \%$ of college students choose to read paper books (Xin \& Wu, 2018). University libraries should focus on the concept of service education, do a good job in information resource construction, use the WeChat platform to link with databases such as Superstar and Boss, and provide readers with a large number of free reading resources to guide students to make full use of the collection resources. Enrich knowledge and broaden horizons.

\subsection{Performing the Reading Function}

University libraries must accurately grasp the reading needs of college students and reading difficulties, and guide college students to establish a correct reading concept and master the correct reading direction. Through the activities of reading salons, big coffee study rooms, etc., we provide navigation services to readers and fulfill the guiding functions of university libraries. The library is a huge cultural treasure, and some readers will feel that they are unable to start with a large number of large seas, Providing navigation services based on the reader's professional characteristics and personal preferences, as well as reading motivation, and helping them improve the quality and efficiency of reading and obtaining effective information. Only choose the right books, can readers be able to read the foundation of literacy, and do not reserve knowledge for the future job.

\subsection{Teaching Reading Methods}

Through Wang Zhen lecture hall, special lectures, and WeChat graphics and other methods, students will be taught some basic reading methods and techniques, and students will be able to feedback the difficult problems encountered in reading to experts and scholars, so that experts and scholars can target them. Recommend students to the most effective reading method and guide students to read in depth (Qiu, 2014). Using the two-way communication features of the WeChat platform can guide students. Only by mastering the method will the efficiency be improved, and the basic reading method will help the reader to absorb and absorb the reading material. The mastery of reading methods and techniques helps to quickly and effectively improve the reading literacy of college students. At the same time, it is necessary to provide readers with practical methods for information retrieval to satisfy the retrieval and utilization of various types of knowledge in the context of big data. 


\subsection{Developing Reading Habits}

The WeChat platform has a recommendation forum and an audio recommendation section, which regularly pushes good books to readers. Currently, 53 issues have been pushed. The recommendation book library mainly promotes the library collection books to the readers, and recommends audio books with sound, which realizes the unification of paper reading and electronic reading. By adopting a recommended book for a fixed period of time twice a week, it is beneficial for readers to develop a habit of reading at a fixed time. "Reading partners, 21 days of card reading" as a reading activity synchronized online and offline, all participants under the leadership of three teachers to read, resist inertia, so that reading and eating and sleeping become the physiological development of the human body Missing activity.

\subsection{Creating a Reading Atmosphere}

Through a series of reading activities such as the Reading Culture Festival, the Reader Service Month, the Graduation Season, the Welcome Season, and the Winter and Summer Vacations. We should give full play to the functions of library in culture educating students, managing educating students, serving educating students. We will further promote borrowing services, subject services and reading promotion. Through lectures, competitions, games and other forms to publicize the collection resources, improve service ability, innovation service mode, expand service connotation, create an atmosphere of campus reading environment. We will attract readers to enter and use the library, and provide a platform for the training of talents in the school. Reward special readers on special festivals such as World Book Day and May Fourth Youth Day. In this way, a positive model leading effect is generated among the readers, which plays an incentive role among the students. Let the college students on campus form a strong atmosphere. Under the influence of this trend, the students in each position will voluntarily belong to the ranks of the team that seeks knowledge (Liu, 2013).

\section{Conclusion}

In the information age with rich reading methods, it is necessary to improve the reading literacy of college students and cultivate their reading ability and habits. It is necessary to give full play to the advantages and functions of university libraries in guiding students to read and serve students, and to do a good job in guiding and serving. Under the existing sophisticated WeChat platform development tools, we use the various functions of the WeChat platform to promote reading and carry out related reading promotion activities. Incorporating with the school's talent training system, comprehensively improving readers' reading literacy and deepening the construction of campus culture, the library can be built into a school's cultural communication base and humanistic literacy training base. 


\section{Acknowledgements}

This paper is a research projects of Heilongjiang Provincial Department of Culture Provincial Art Planning Project "Research on Cultural Construction in Rural Revitalization Strategy" (Project Number: 2018D024); Daqing Philosophy and Social Science Planning "Study on the Strategy of University Library to Promote the Construction of New Rural Culture in Daqing under the Background of Big Data" (Project Number: DSGB2018129); Heilongjiang Bayi Agricultural University Intramural subject of "Application and Research of Micro Platform in Library Information Service” funded by (Project Number: XRW2014-18).

\section{Conflicts of Interest}

The author declares no conflicts of interest regarding the publication of this paper.

\section{References}

He, L. X., \& Wang, Y. L. (2017). Teaching Logic and Reform Strategy of Reading Literacy. Chinese Education Journal, 4, 71-76.

Ji, Y. J., \& Wang, X. Y. (2014). Comparison of Reading Situations of College Students at Home and Abroad and Reflections on Reading Education and Promotion in University Libraries. Library Journal, 8, 65-69 + 52 .

Li, L. N. (2017). Research and Application of University Library Information Service Based on WeChat Public Platform. Journal of Agricultural Library and Information Sciences, 3, 182-185.

Liu, M. (2013). Research on the Development Strategy of University Library Service under the Cognition of Students' Reading Literacy. Journal of Changchun Institute of Education, 1, 112-113.

Qiu, J. J. (2014). The Status Quo of College Students' Reading Literacy and the Countermeasures of University Libraries. Journal of Hunan Institute of Science and Technology, $8,176-177$.

Xin, H. X., \& Wu, H. R. (2018). Investigation and Analysis of College Students' Reading Status under the Environment of Social Network. Library Research and Work, 6, 54-58.

Yu, X. J., Song, N. Q., \& Wang, Y. L. (2017). Changes in the Content of PISA2018 Reading Literacy Test and Its Reference to Chinese Reading Teaching. Comparative Education Research, 5, 3-10.

Zhang, S. S. (2017). Adherence and Innovation: Review and Enlightenment of PIRLS Reading Literacy Evaluation. Global Education Outlook, 2, 58-66. 